\title{
miR-204 Negatively Regulates Cell Growth And Metastasis By Targeting ROBO4 In Human Bladder Cancer
}

This article was published in the following Dove Press journal: OncoTargets and Therapy

\author{
Yang $\mathrm{Li}^{1, *}$ \\ Rong Chen ${ }^{2, *}$ \\ Zun $\mathrm{Li}^{\prime}$ \\ Hepeng Cheng' \\ Xiaodong $\mathrm{Li}^{\prime}$ \\ Tieqiang $\mathrm{Li}^{1}$ \\ Chaoyang Zhu' \\ 'Department of Urology, Henan \\ University Huaihe Hospital, Kaifeng \\ 475000, People's Republic of China; \\ 2Department of Urology, Zhuji People's \\ Hospital of Zhejiang Province, Zhuji \\ 3II800, China
}

*These authors contributed equally to this work
Correspondence: Chaoyang Zhu

Department of Urology, Henan University Huaihe Hospital, No. 8 Baobei Road,

Kaifeng, Henan Province 475000, People's Republic of China

Email chaoyangz_hn@163.com
Background: MicroRNAs (miRNAs) are well characterized for their important roles in human cancers by influencing various aspects of malignancy. Till now, the function and mechanism of miR-204, a tumor suppressor in several cancers, remain unclear in bladder cancer $(\mathrm{BC})$. Here, we intend to explore its roles in $\mathrm{BC}$ progression.

Methods: qRT-PCR was applied to determine miR-204 and ROBO4 expression in BC tissues and cell lines. miR-204 expression with clinicopathological features was analyzed. The impacts of miR-204 on BC cell growth and metastasis in vitro were evaluated by both loss-of-function and gain-of-function assays (CCK-8, crystal violet staining, wound healing and transwell assays). Furthermore, qRT-PCR, Western blot and luciferase reporter assays were used to validate the targeting of ROBO4 by miR-204. Finally, linear regression was performed to analyze the correlation of miR-204 and ROBO4 in BC tissues.

Results: Expression of miR-204 was markedly decreased in $\mathrm{BC}$ tissues and cell lines were compared with respective controls. Low miR-204 expression was associated with positive advanced $\mathrm{T}$ stage and lymph node metastasis. Cellular function studies revealed that miR-204 inhibited $\mathrm{BC}$ cell growth, migration and invasion. Mechanistic exploration found that miR204 directly targeted ROBO4. Rescue assays indicated that ROBO4 restoration could reverse the antitumor effects of miR-204 in BC. Finally, ROBO4 was significantly correlated with miR-204 levels inversely.

Conclusion: miR-204 might serve as a tumor suppressor in $\mathrm{BC}$ by targeting ROBO4.

Keywords: BC, miR-204, ROBO4, cell growth and metastasis

\section{Introduction}

As is known, bladder cancer (BC) is a prevalent urogenital malignancy with considerable high morbidity and mortality rates worldwide. ${ }^{1,2}$ The global community expects incidence of approximately 430,000 cases and mortality of 165,000 cases annually. ${ }^{3}$ Suffering from this disease causes a substantial health-related economic burden for many families every year. ${ }^{4}$ Surgical resection combined with radio- and chemotherapy is the preferred treatment strategy for BC patients. After years of effort on improvement in $\mathrm{BC}$ therapy, the overall mortality rate slightly declined. ${ }^{5}$ However, for those patients in advanced stages or with metastasis, the five-year survival remains largely dissatisfied. ${ }^{6}$ Tumorigenesis is described as a result of disequilibrium of innate immune system. ${ }^{7}$ A better understanding of the molecular mechanism governing BC carcinogenesis and progression will benefit the target development on early diagnosis, treatment and prognosis prediction of $\mathrm{BC}$ patients. 
MicroRNAs (miRNAs) are endogenous non-coding RNAs consisting of roughly 19-24 nucleotides. They exert post-transcriptional gene repression effects by base-pairing to the $3^{\prime}$-untranslated region ( $\left.3^{\prime} \mathrm{UTR}\right)$ of the targeted mRNAs, therefore leading to mRNA degradation or translation inhibition. ${ }^{8,9}$ As the research moves along, miRNAs are known to be implicated in almost every aspect of physiological and pathological processes, among which their roles in tumorigenesis are most frequently reported. ${ }^{10,11,12}$ Increasing evidence suggests that miRNAs are aberrantly expressed in human cancers, and their abnormal expression could be used as novel biomarkers for cancer diagnosis, therapy and prognosis. ${ }^{13,14}$ Moreover, according to the specific cell context or micro-environment, miRNAs can act as oncogenes or tumor suppressors and impact on cell growth, apoptosis, migration and invasion. ${ }^{15}$ In $\mathrm{BC}$, several miRNAs are summarized for their roles and potential clinical values. ${ }^{16,17}$ Recently, the expression of miR-204 was reported to be decreased and suppressed cancer behaviors in several kinds of cancers, including in gastric cancer, breast cancer and colorectal cancer. ${ }^{18,19,20}$ However, its expression, function and mechanism in $\mathrm{BC}$ have not yet been investigated and need further attention.

Our previous bioinformatics prediction implied that Roundabout 4 (ROBO4) might be a target of miR-204. The ROBO family members are highly conserved transmembrane cell adhesion proteins that mainly contribute to the development of the nervous system. ${ }^{21}$ Slit is the ligand of ROBO, which could regulate neuronal cell proliferation and migration. ${ }^{21}$ The Slit/ROBO pathway is essential for tumor angiogenesis. ${ }^{22}$

In this study, we took advantage of molecular and cellular technologies and found that miR-204 substantially inhibited $\mathrm{BC}$ cell growth, migration and invasion in vitro by targeting ROBO4. Our data clearly illustrated that the miR-204 might be a potential therapeutic target for BC.

\section{Materials And Methods}

\section{Patients And Tissues}

A total of 36 bladder cancer tissues and adjacent nontumoral tissues were collected from 36 patients who underwent transurethral resection of the bladder at the Henan University Huaihe Hospital (Kaifeng, China) between January 2017 and December 2017. All these 36 patients were enrolled prospectively and in a randomized way. This study was approved by the Ethics Committee of the Henan University Huaihe Hospital (Kaifeng, China).
Written informed consent was obtained from all patients. After surgical removal, all tissues were snap-frozen immediately in liquid nitrogen and stored at $-80^{\circ} \mathrm{C}$ before used.

\section{Cell Culture}

The normal human bladder epithelial cell line SV-HUC-1 and the bladder cell lines (HT-1197, HT-1376, J82, RT4, T24, 5637) were from the American Type Culture Collection (Manassas, VA, USA). Cells were cultured in RPMI 1640 medium (HyClone, USA) supplemented with $10 \%$ fetal bovine serum (FBS; Thermo Fisher Scientific, Inc., Waltham, MA, USA) at $37^{\circ} \mathrm{C}$ with $5 \% \mathrm{CO}_{2}$.

\section{miRNAs, Plasmids And Transfections}

The miR-204-3p mimics, miR-204-3p inhibitor and miRNA controls were chemically synthesized by RiboBio Co., Ltd. (Guangzhou, China). The vector expressing ROBO4 sequence was amplified by PCR technology from 5637 cDNAs and cloned into pcDNA3.1 vector. The transfections were performed by using Lipofectamine 3000 Reagent as per the manufacturer's protocol (Thermo Fisher Scientific, Inc., Waltham, MA, USA).

\section{Quantitative Real-Time Polymerase Chain Reaction}

TRIzol reagent (Thermo Fisher Scientific, Inc., Waltham, MA, USA) was applied for extracting total RNA containing miRNA to quantitate the miR-204-3p expression in bladder cancer tissues and cell lines. RNA was reverse transcribed using M-MLV Reverse Transcriptase from Promega (Promega, Madison, WI, USA) as per the manufacture's introduction. Expression levels of miR-204-3p were normalized to that of rRNA U6B and then converted into relative values calculated by the comparative $\mathrm{CT}$ method. The primers of miR-204-3p and U6B were purchased from RiboBio Co., Ltd. (Guangzhou, China). qRTPCR was performed through the SYBR Premix Ex Taq (Takara Bio, Inc., Otsu, Japan) on an ABI PRISM 7900 Real-time PCR system (Applied Biosystems, Thermo Fisher Scientific, Inc., Waltham, MA, USA). GAPDH was used as control of ROBO4. The primers were designed as follows:

GAPDH:

F: 5'-GAGTCA ACGGATTTGGTCGT-3', R: 5'-TTGATTTTGGAGGGA TCTCG-3'; ROBO4:

F: 5'-CATCCGCTGGTTGCTGAATG-3', 


\section{R: 5'-CTGTAGCAGCAGAAGGGTCC-3'.}

The relative expression levels were analyzed using the $2^{-\Delta \Delta} \mathrm{Ct}$ method.

\section{Cell Counting Kit-8 (CCK-8) Assay}

Cell viability ability was assessed by CCK-8 (Dojindo, Kumamoto, Japan) assays using microplate reader (SpectraMax M5, Molecular Devices, USA). Approximately $3 \times 10^{3}$ transfected cells were seeded in each well of 96-well plates and incubated for $0,24,48$, 72 and $96 \mathrm{hrs}$. According to the manufacturer's instruction, the cells of each well were added with $10 \mu \mathrm{L}$ CCK-8and cultured for $1 \mathrm{hr}$ at $37^{\circ} \mathrm{C}$ before the optical density (OD) was determined at $450 \mathrm{~nm}$ by the microplate reader.

\section{Crystal Violet Staining Assay}

Cell proliferation ability was assessed by crystal violet staining assay. Briefly, $48 \mathrm{hrs}$ after transfection, cells were washed twice by ice-cold PBS and fixed in $4 \%$ formaldehyde solution for 20mins. After wash, the cells were stained with $0.5 \%$ crystal violet solution for $30 \mathrm{mins}$. The plates were aspirated, washed and allowed to air dry. As high as $10 \%$ acetic acid was added to each well to dissolve the crystal and incubated for $30 \mathrm{mins}$ with shaking. The absorbance was read at $590 \mathrm{~nm}$ by the microplate reader (SpectraMax M5, Molecular Devices, USA).

\section{Flow Cytometry Assay}

Cell cycle distribution was assessed by flow cytometry assay. The cells were fixed with $70 \%$ ice-cold ethanol at $-20^{\circ} \mathrm{C}$ overnight. After that, the fixed cells were stained with propidium iodide solution (Sigma-Aldrich, St. Louis, MO, USA) and incubated at $37^{\circ} \mathrm{C}$ in darkness for $30 \mathrm{mins}$. DNA content was examined by flow cytometry using a FACSCalibur.

\section{Wound Healing Assay}

Cell migration ability was assessed by wound healing assay. Briefly, after the transfected cells reached $90 \%$ confluence in 6-well plates, a straight wound was artificially scratched by a $1000 \mu \mathrm{L}$ pipette tip (Axygen, USA). The detached cells were removed by PBS and maintained in humidified incubator at $37^{\circ} \mathrm{C}$ containing $5 \% \mathrm{CO}_{2}$. The images of wound closure were photographed at 0 and $72 \mathrm{hrs}$ with a microscope (Olympus Corporation, Tokyo, Japan).

\section{Transwell Assay}

Cell invasive ability was assessed by using Transwell chambers (BD Biosciences, New York, NJ, USA) coated with Matrigel (BD Biosciences, New York, NJ, USA) according to the manufacturer's instructions. Briefly, $24 \mathrm{hrs}$ after transfection, the cells were harvested, counted and suspended in $200 \mu \mathrm{L}$ serum-free 1640 and added into the top chamber. The bottom chamber was imbued with $500 \mu \mathrm{L} 1640$ medium containing 10\% FBS. After incubation for $72 \mathrm{hrs}$, the invaded cells were fixed with $4 \%$ formaldehyde solution and stained with $0.5 \%$ crystal violet solution. The cells were counted in six different fields using a digital camera system (Olympus Corporation, Tokyo, Japan).

\section{Dual-Luciferase Reporter Assay}

To construct the pmir-ROBO4-3' UTR (WT) plasmid that contained the potential binding sites of ROBO4 3' UTR downstream of the firefly luciferase gene, a fragment was amplified and inserted into the pmirGLO Dual-Luciferase miRNA Target Expression Vector (Promega Corporation, Fitchburg, WI, USA). 5637 and HT-1376 cells were cotransfected with luciferase plasmid and miR-204 mimics or controls using Lipofectamine 3000 Reagent (Thermo Fisher Scientific, Inc., Waltham, MA, USA). Mutations in the miR-204-binding site of ROBO4 3' UTR were introduced by the Phusion Site-Directed Mutagenesis Kit (Thermo Fisher Scientific, Inc., Waltham, MA, USA) as per manufacturer's instructions. Forty-eight hours after transfection, luciferase activity was measured by using the Dual-Luciferase Reporter Assay System (Promega Corporation, Fitchburg, WI, USA). Then, the firefly luciferase activity was normalized to the corresponding Renilla luciferase activity. Data are presented from triplicate experiments.

\section{Western Blot Analysis}

Tissue protein and cellular proteins were extracted from cells using RIPA Buffer (Beyotime, Beijing). Proteins were separated by $8 \%$ sodium dodecyl sulfate polyacrylamide gel electrophoresis (SDS-PAGE) and then transferred onto nitrocellulose membrane (Millipore, USA). The membranes were blocked with $5 \%$ skim milk in PBST for $1 \mathrm{hr}$ at room temperature and incubated overnight at $4^{\circ} \mathrm{C}$ with primary antibodies. The antibodies against ROBO4 (sc-166872, 1:1000) and $\beta$-actin (sc-8432, 1:4000) were purchased from Santa Cruz (Dallas, TX, 
USA). After incubating with peroxidase-conjugated secondary antibodies (Beyotime, Beijing), the members were developed with an enhanced chemiluminescence detection kit (Millipore, USA).

\section{Target Prediction}

The online available databases TargetScan (www.targets can.org/vert 71) was used to predict the candidate targets of miR-204-3p.

\section{Statistical Analysis}

Statistical analysis was performed using GraphPad Prism 6 Software (GraphPad Software, Inc., San Diego, CA, USA). Comparisons between two groups were performed using a two-tailed paired or grouped $t$-test. The comparisons of three or more groups were performed using oneway analysis of variance (ANOVA). Correlation between miR-204 expression and clinicopathological features was performed by $\chi^{2}$ test. All data are expressed as means \pm SD. Statistical significance was set at $P<0.05$.

\section{Results}

\section{miR-204 Is Downregulated In BC}

A total of 36 pairs of human BC samples and their adjacent non-tumoral tissues were collected and used for miR-204 expression detection. qRT-PCR results showed that comparing with the paired non-tumoral tissues, miR-204 levels were significantly decreased in cancerous BC tissues (Figure 1A). Then, we determined miR-204 expression in several BC cell lines and found that miR-204 was consistently downregulated in all BC cell lines used (HT-1197, HT-1376, J82, RT4, T24 and 5637) when compared with that in a normal bladder epithelial cell line (SV-HUC-1; Figure 1B). The miR-204 downregulation in $\mathrm{BC}$ indicates its putative tumor-suppressing role in $\mathrm{BC}$ development. To better understand the clinical significance of miR-204 expression in BC, we analyzed the correlation of miR-204 expression in human BC samples with a series of clinicopathological features. As shown in Table $1, \chi^{2}$ analysis revealed that low miR-204 expression in BC samples was associated with advanced $\mathrm{T}$ stage $(\mathrm{P}<0.05)$ and lymph node metastasis $(\mathrm{P}<0.05)$, but not with other clinicopathological features $(\mathrm{P}>0.05)$.

\section{miR-204 Inhibits Cell Growth, Migration And Invasion Of BC Cells}

Based on the above expression results of miR-204, we then set to investigate the effects of miR-204 overexpression or inhibition on $\mathrm{BC}$ cell growth and metastasis processes. 5637 and HT-1376 cell line was selected as the cellular model since it expressed the modest level of miR-204. We ordered commercially available mimics and inhibitor of miR-204 to achieve its transient
A

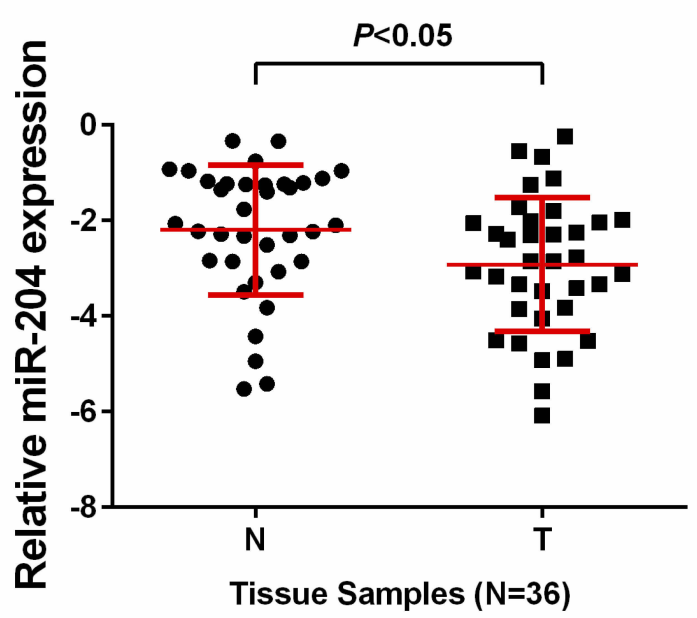

B

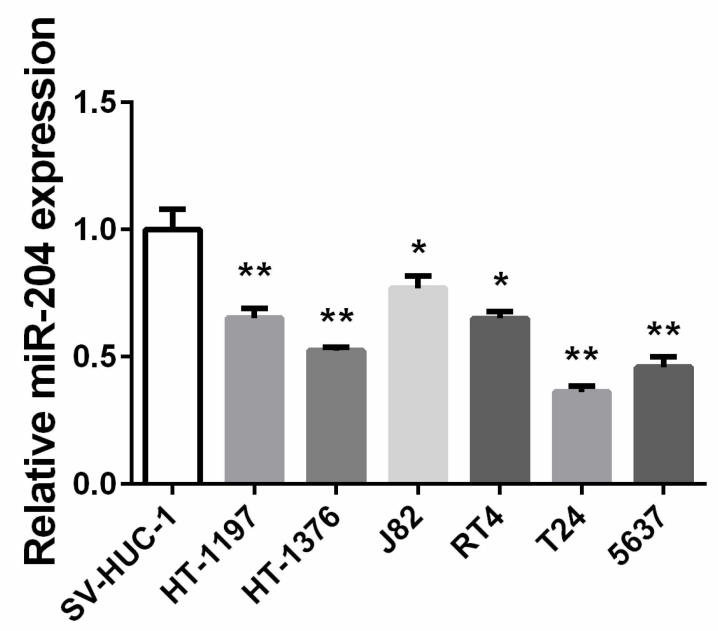

Figure I miR-204 is downregulated in bladder cancer. (A) The miR-204 expression in bladder cancer tissues compared with that in adjacent non-tumoral tissues was assessed by qRT-PCR. (B) The miR-204 expression in bladder cancer cell lines (HT-II97, HT-I376, J82, RT4, T24, 5637) compared with that in normal human bladder epithelial SV-HUC-I cells was assessed by qRT-PCR. $* P<0.05$, $* * P<0.01$. 
Table I Association Between The Expression Of miR-204-3p And Clinicopathologic Feature In Bladder Cancer Patients

\begin{tabular}{|c|c|c|c|c|}
\hline $\begin{array}{l}\text { Clinicopathological } \\
\text { Features }\end{array}$ & No. Of Samples & $\begin{array}{l}\text { Downregulated } \\
\text { miR-204-3p }(n=19)\end{array}$ & $\begin{array}{l}\text { Non-Downregulated } \\
\text { miR-204-3p }(n=17)\end{array}$ & $P$ Value \\
\hline $\begin{array}{l}\text { Age (years) } \\
\quad<60 \\
\geq 60\end{array}$ & $\begin{array}{l}20 \\
16\end{array}$ & $\begin{array}{l}11 \\
8\end{array}$ & $\begin{array}{l}9 \\
8\end{array}$ & 0.7652 \\
\hline $\begin{array}{l}\text { Sex } \\
\text { Female } \\
\text { Male }\end{array}$ & $\begin{array}{l}23 \\
13\end{array}$ & $\begin{array}{l}12 \\
7\end{array}$ & $\begin{array}{l}11 \\
6\end{array}$ & 0.9231 \\
\hline $\begin{array}{l}\text { Tumor size (cm) } \\
<3 \\
\geq 3\end{array}$ & $\begin{array}{l}22 \\
14\end{array}$ & $\begin{array}{l}13 \\
6\end{array}$ & $\begin{array}{l}9 \\
8\end{array}$ & 0.3415 \\
\hline $\begin{array}{l}\text { T stage } \\
\mathrm{Ta}+\mathrm{T} \text { is }+\mathrm{Tl} \\
\mathrm{T} 2+\mathrm{T} 3+\mathrm{T} 4\end{array}$ & $\begin{array}{l}19 \\
17\end{array}$ & $\begin{array}{l}7 \\
12\end{array}$ & $\begin{array}{l}12 \\
5\end{array}$ & $0.0429^{*}$ \\
\hline $\begin{array}{l}\text { LN metastasis } \\
\text { Absent } \\
\text { Present }\end{array}$ & $\begin{array}{l}21 \\
15\end{array}$ & $\begin{array}{l}8 \\
11\end{array}$ & $\begin{array}{l}13 \\
4\end{array}$ & $0.0368^{*}$ \\
\hline $\begin{array}{l}\text { Tumor number } \\
\text { Single } \\
\text { Multiple }\end{array}$ & $\begin{array}{l}25 \\
11\end{array}$ & $\begin{array}{l}14 \\
5\end{array}$ & $\begin{array}{l}11 \\
6\end{array}$ & 0.5593 \\
\hline $\begin{array}{l}\text { Differentiation } \\
\text { Well+ Moderately } \\
\text { Poorly }\end{array}$ & $\begin{array}{l}27 \\
9\end{array}$ & $\begin{array}{l}15 \\
4\end{array}$ & $\begin{array}{l}12 \\
5\end{array}$ & 0.5631 \\
\hline
\end{tabular}

Note: $* \mathrm{P}<0.05$.

overexpression and inhibition, respectively. Firstly, qRT-PCR confirmed that miR-204 mimics or inhibitor work efficiently by transfection in 5637 and HT-1376 cells (Figure 2A). The viability rate was monitored by CCK-8 assay. As shown in Figure 2B, following miR-204 overexpression, cell viability was obviously slowed down, while miR-204 inhibition led to elevated viability rate (Figure 2B). Accordingly, crystal violet staining verified that miR-204 overexpression caused reduced proliferation, and miR-204 inhibition resulted in enhanced proliferation (Figure 2C). Besides, we have investigated how miR-204 impacts BC cell growth. Flow cytometry assay was performed to determine the cell cycle distribution. We found that overexpression of miR-204 resulted in significantly G1 phase arrest in 5637 and HT-1376 cells (Supplementary Figure 1).

To further explore the impact of miR-204 on BC cell metastasis, we next performed wound healing and transwell invasion assays to evaluate the alteration of migration and invasion abilities caused by miR-204 overexpression or inhibition. We found that miR-204 mimics transfection reduced the migration and invasion abilities compared with that in control cells, while miR-204 inhibitor transfection led to the opposite (Figure 3A and B). These results suggest that miR-204 possesses tumor inhibitory activities by suppressing cell growth and metastasis in $\mathrm{BC}$ cells.

\section{ROBO4 Is Specifically Targeted By miR-204}

To understand the internal molecular mechanism of miR-204 in BC cells, we predicted its putative mRNA targets by using the bioinformatics algorithm TargetScan. As a result, 3'UTR of ROBO4 was predicted to contain a highly conserved binding site for miR-204 (Figure 4A). To confirm whether ROBO4 was truly a target of miR-204 in BC cells, we constructed both the wild type (WT) and mutant type (MUT) luciferase reporter containing the seeding sequence (in green) and mutant seeding sequence (in red) in $3^{\prime}$ UTR 


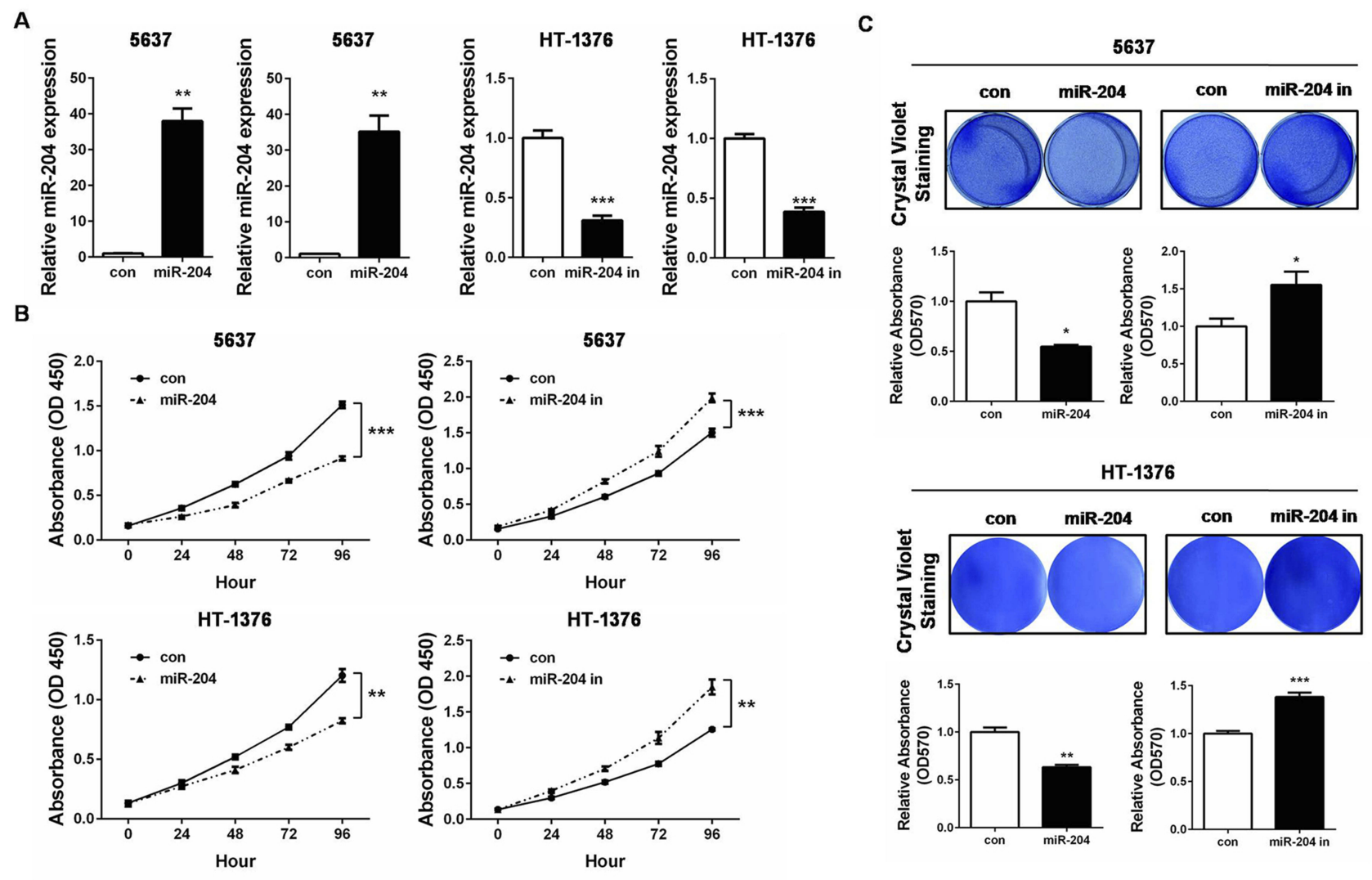

Figure 2 miR-204 inhibits cell growth of bladder cancer cells. (A) 5637 and HT-1376 cells were transfected with miR-204 mimics or inhibitor, respectively. After transfection, qRT-PCR was performed to examine the expression of miR-204. (B) Cell viability was measured by CCK-8 Assay at 0, 24, 48, 72 and 96hrs after miR-204 mimics or inhibitor transfection. (C) Crystal violet staining assay was conducted to evaluate cell proliferation after miR-204 mimics or inhibitor transfection. The quantitative results were shown in right panel. $* P<0.05$, $* * P<0.01$, $* * * P<0.001$.

of ROBO4 (Figure 4A). 5637 and HT-1376 cells were co-transfected with the indicated dual-luciferase reporter plus miR-204 mimics, and the luciferase activity was measured. As shown in Figure 4B, miR-204 mimics transfection induced a substantial decline of the WT luminescence intensity, while the MUT reporter remained impervious by miR-204 overexpression. Following qRT-PCR and Western blot further revealed that miR-204 overexpression induced ROBO4 suppression on both mRNA and protein levels (Figure $4 \mathrm{C}$ and D). Therefore, we confirmed that $\mathrm{ROBO} 4$ is a direct target of miR-204 in BC cells.

\section{ROBO4 Mediates The Tumor-Suppressing Role Of miR-204 In BC}

As the latest identified $\mathrm{ROBO}$ receptor, ROBO4 was previously proved to be implicated in $\mathrm{BC}$ tumorigenesis. $^{23}$ We then questioned whether miR-204 exerted tumor-suppressing effects by targeting ROBO4 in $\mathrm{BC}$ cells. To this end, we synthesized ROBO4 expression plasmid and introduced it into the miR-204-overexpressed cells. Both qRT-PCR and Western blot validated the restoration of ROBO4 in the dual-transfected cells (ROBO4+miR-204 mimics; Figure 5A and B). Importantly, we observed that ROBO4 re-expression significantly rescued the impaired cell proliferation and migration caused by miR-204 overexpression as assessed by crystal violet staining and wound healing assay, respectively (Figure 5C and D). Finally, we found ROBO4 mRNA levels negatively correlated with the expression of miR-204, highlighting the targeting of ROBO4 by miR-204 in BC tissues (Figure 5E). Therefore, our data indicate that the inhibitory effects of miR-204 on BC cell growth and migration are mediated by $\mathrm{ROBO} 4$.

\section{Discussion}

Mounting evidence illustrated that miRNAs are promising biomarkers and therapeutic targets for human 
A

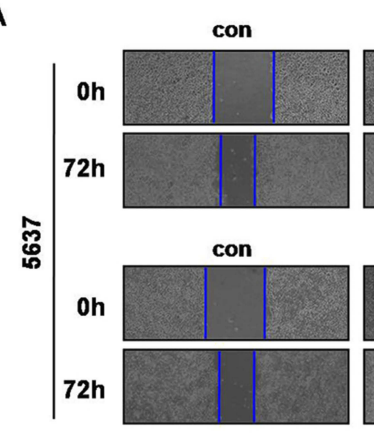

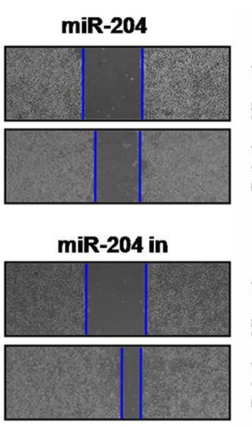
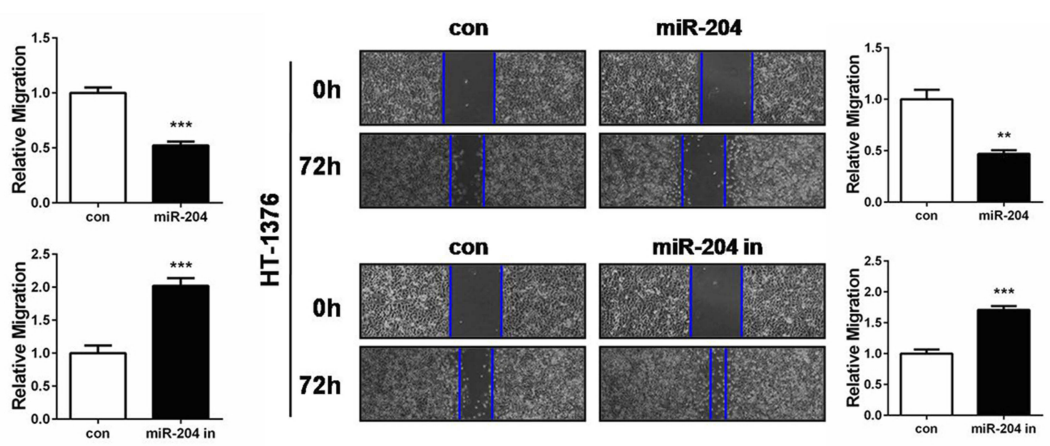

B

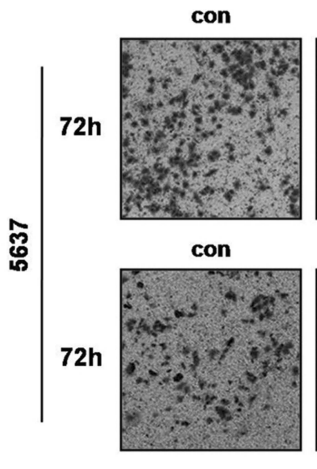
miR-204

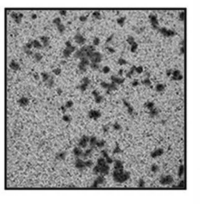
miR-204 in
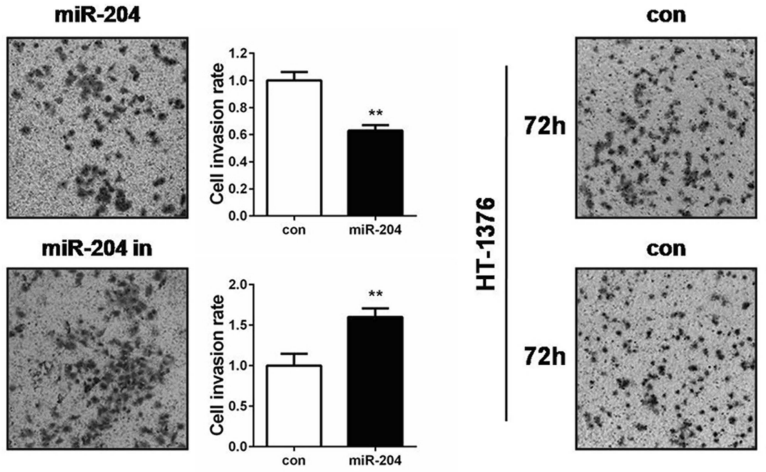

miR-204
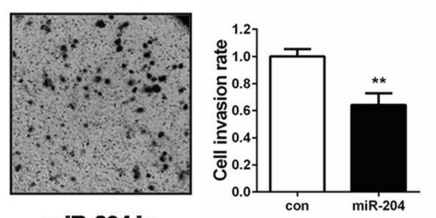

miR-204 in
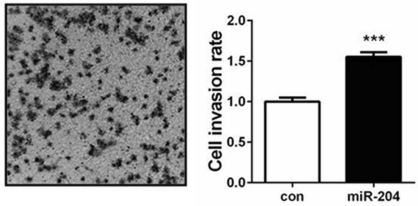

Figure 3 miR-204 inhibits cell migration and invasion of bladder cancer cells. (A) Cell migration ability was investigated with wound healing assay and the images were taken at 0 and $72 \mathrm{hrs}$ after miR-204 mimics or inhibitor transfection (40x). (B) Cell invasion ability was investigated with transwell assay and the images were taken at $72 \mathrm{hrs}$ after miR-204 mimics or inhibitor transfection (I00x). Representative images are shown (left panel). The quantitative results represent the mean \pm SD in triplicate using the bar graph (right panel). $* * P<0.01$, $* * * P<0.001$.

cancers since their first function investigation in cancer. ${ }^{24}$ MiRNAs are abnormally expressed in several malignancies including in urologic neoplasms. ${ }^{14,25,26}$ They play pivotal roles in cancer development, progression and metastasis. ${ }^{26}$ For miR-204, although its decreased expression and antitumor effects have been observed in other types of human malignancies, ${ }^{18-20}$ its specific role in $\mathrm{BC}$ remains unknown. To clarify this, we designed in vitro experiments and showed that miR-204 was downregulated in both BC tissues and cell lines in comparison with their controls. More importantly, through the function assays, we demonstrated that miR-204 exerted tumor-suppressing activities by inhibiting cell growth, migration and invasion in BC cells. The downregulation and antitumor effects of miR-204 are the same with its roles in other kinds of human malignancies. ${ }^{18,20}$

To understand the mechanism of miR-204 in BC, we predicted its putative targets and identified that $\mathrm{ROBO} 4$ was a direct target of miR-204. Transmembrane ROBO proteins are receptors for Slits, the secreted glycoproteins, and Slit/ROBO signaling is mainly involved in mediating axon guidance. ${ }^{21}$ Recent expanding progress on this signaling reveals its implication in angiogenesis and cancer progression. ${ }^{21,22}$ ROBO4 is the latest identified ROBO specifically expressed in the endothelial cells and at the site of neoangiogenesis, suggesting its potential roles in tumor growth. ${ }^{27,28}$ Our previous study investigating the effect of blocking ROBO on the urinary bladder urothelium carcinoma tumor transplantation in nude mice demonstrated that tumors in $\mathrm{ROBO} 4$ blocking group were significantly smaller than those in the control group, ${ }^{23}$ firstly indicating the tumor-promoting role of ROBO4 in BC. Here, we found an upstream regulator, miR-204, on ROBO4 expression in $\mathrm{BC}$ cells. Moreover, our function assays demonstrated that restoration of ROBO4 in miR-204-overexpressed cells rescued the impaired cell viability and migration caused by miR-204 overexpression. These data supported that ROBO4 was an essential mediator of the antitumor effects of miR-204 in BC cells. As is known, one particular miRNA might target various mRNAs simultaneously. The functional outcome of one miRNA is the balance result of its oncogenic targets versus 
A

Position 300-308 of ROBO4 3' UTR (WT) $\quad 5^{\prime} \quad$...UGAGGAGCAGCCCUCCCUGCUCC... $3^{\prime}$

hsa-miR-214-3p

3' UGACGGACAGACACGGACGACA $5^{\prime}$

| | | | | | | |

Position 300-308 of ROBO4 3' UTR (MUT) $5^{\prime}$...UGAGGAGCAGCCCACGGACGACC... $3^{\prime}$

B

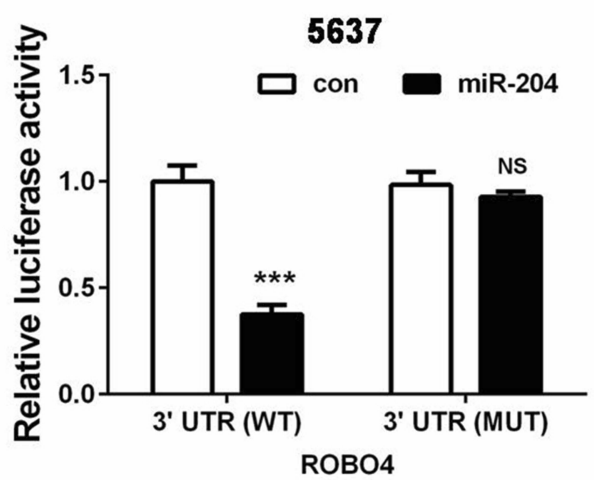

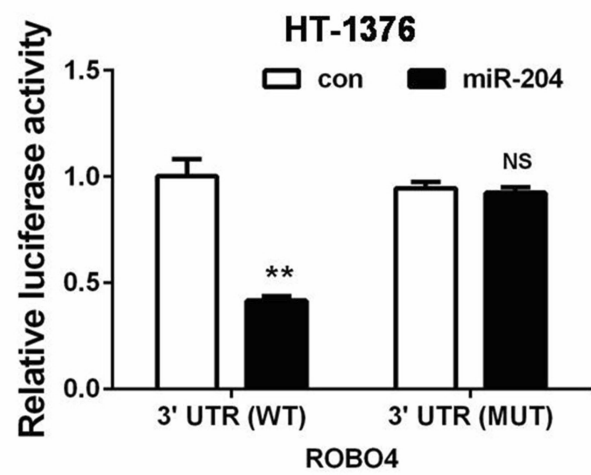

C
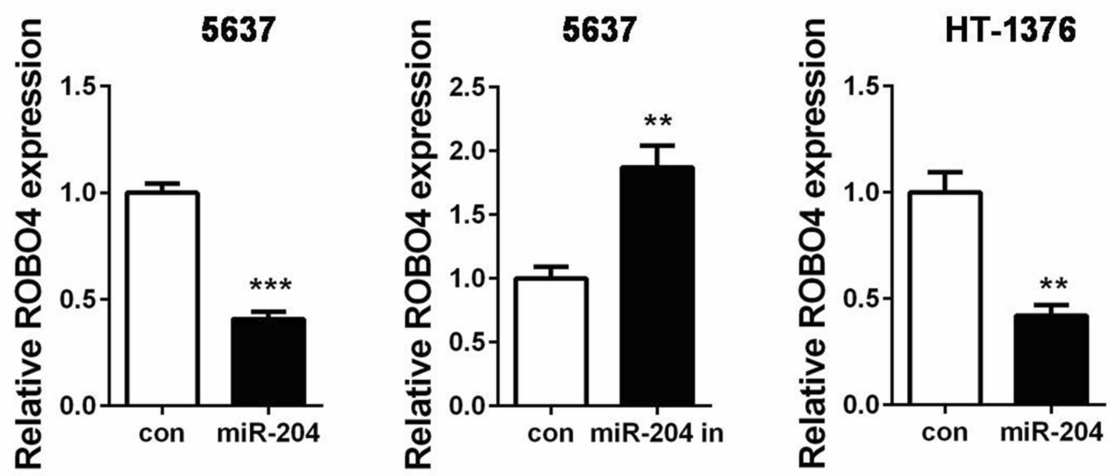

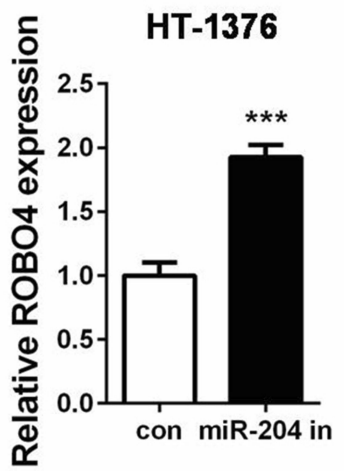

D

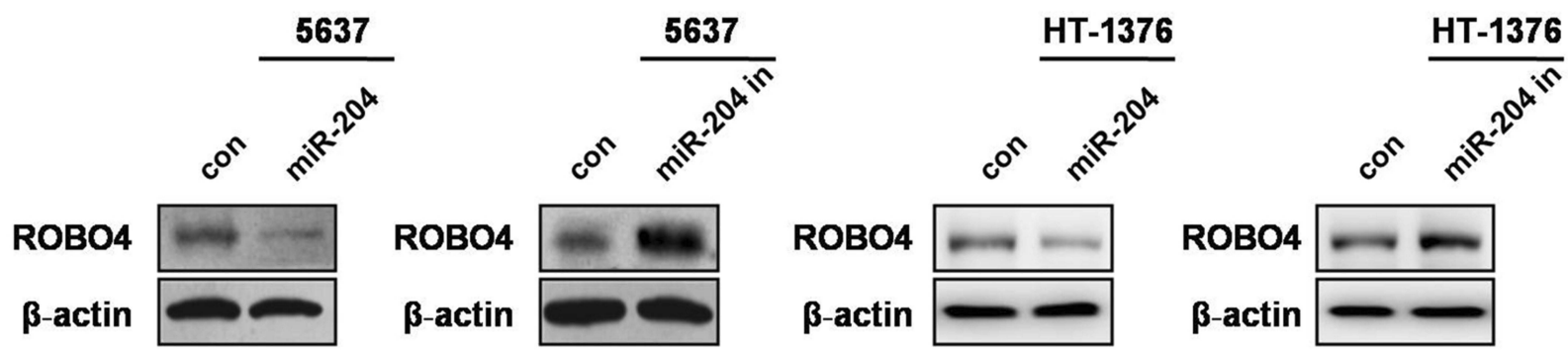

Figure 4 ROBO4 is a direct target of miR-204. (A) Bioinformatics analysis predicts that ROBO4 is a putative target gene of miR-204. The luciferase reporter plasmid containing ROBO4 3' UTR (WT, in green) and ROBO4 3' UTR (MUT, in red) was generated. (B) Luciferase activity assay was performed in 5637 and HT- I376 cells cotransfected with miR-204 mimics and a dual-luciferase reporter containing the ROBO4 3' UTR (WT) and ROBO4 3' UTR (MUT). (C) The expression of ROBO4 in 5637 and HT-I376 cells $48 \mathrm{hrs}$ after transfection with miR-204 mimics or controls was measured by qRT-PCR. (D) The expression of ROBO4 in 5637 and HT-I376 cells after 48hrs transfection with miR-204 mimics or controls was measured by Western blot analysis. $* * P<0.01$, $* * * P<0.001$.

Abbreviations: WT, wild-type; MUT, mutant.

tumor-suppressing targets. We believe that miR-204 should have additional targets that could explain its roles in $\mathrm{BC}$, whereas $\mathrm{ROBO} 4$ stands for an important one.
To conclude, our study presents novel findings that a) miR-204 is downregulated in human $\mathrm{BC}$; b) miR-204 is a functional tumor suppressor in $\mathrm{BC}$; c) miR-204 directly targets $\mathrm{ROBO} 4$ and (d) targeting of ROBO4 is 
A

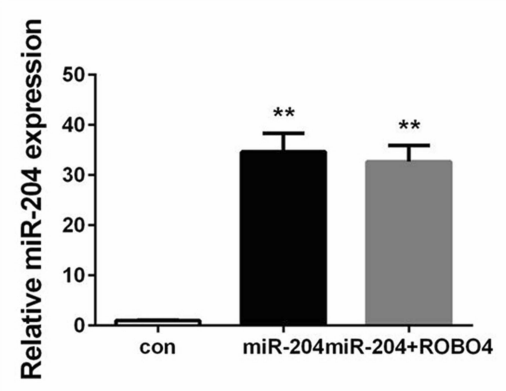

C
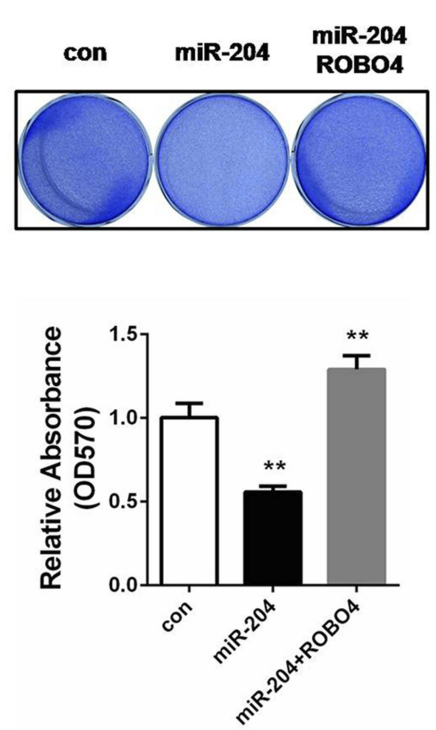

B
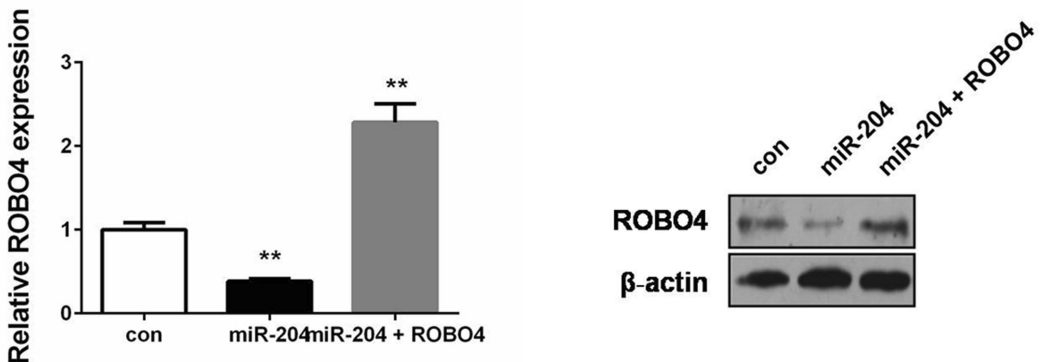

D
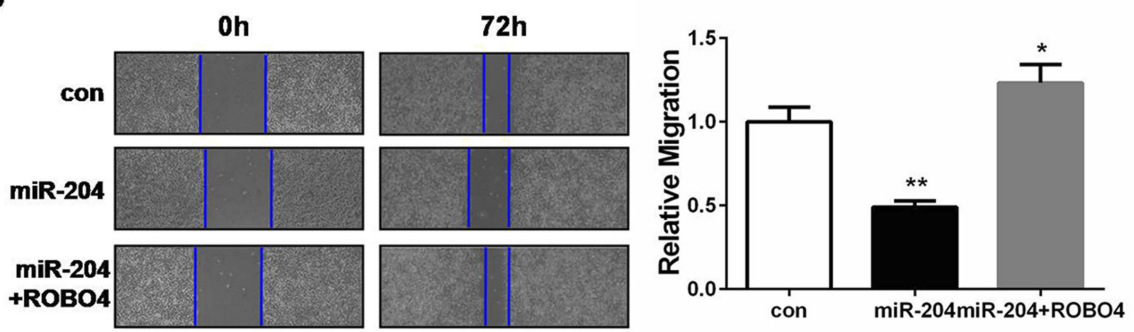

$\mathrm{E}$

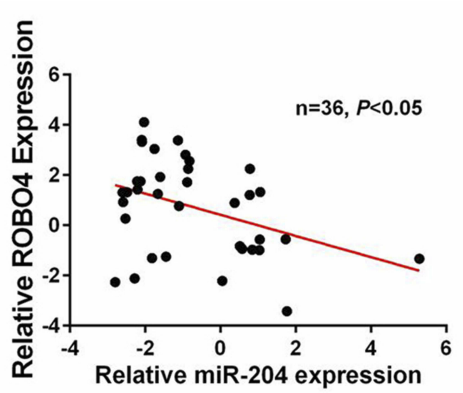

Figure 5 miR-204 mediates a tumor-suppressing role through ROBO4 in bladder cancer. (A) The expressions of miR-204 and ROBO4 in 5637 cells 48 hrs after transfection with miR-204 mimics without or with ROBO4 plasmids were measured by qRT-PCR. (B) The expressions of miR-204 and ROBO4 in 5637 cells 48 hrs after transfection with miR-204 mimics without or with ROBO4 plasmids were measured by Western blot analysis. (C) Crystal violet staining assay was conducted to evaluate cell proliferation after miR-204 mimics without or with ROBO4 plasmids transfection. The quantitative results were shown in panel below. (D) Cell migration ability was investigated with wound healing assay and the images were taken at 0 and $72 \mathrm{hrs}$ after miR-204 mimics without or with ROBO4 plasmids transfection (40x). (E) miR-204 and ROBO4 expression levels exhibited negative correlation. $* * P<0.01$.

responsible for the antitumor effects of miR-204. Therefore, the miR-204/ROBO4 axis might be used as an interesting molecular candidate for $\mathrm{BC}$ targeted therapy.

\section{Acknowledgments}

This work was supported by the Science and Technology Project of Henan Province (No. 152102310076).

\section{Disclosure}

The authors report no conflicts of interest in this work.

\section{References}

1. Antoni S, Ferlay J, Soerjomataram I, Znaor A, Jemal A, Bray F. Bladder cancer incidence and mortality: a global overview and recent trends. Eur Urol. 2017;71(1):96-108. doi:10.1016/j.eururo.2016.06.010
2. Dy GW, Gore JL, Forouzanfar MH, Naghavi M, Fitzmaurice C. Global burden of urologic cancers, 1990-2013. Eur Urol. 2017;71 (3):437-446. doi:10.1016/j.eururo.2016.10.008

3. Poli G, Brancorsini S, Cochetti G, Barillaro F, Egidi MG, Mearini E. Expression of inflammasome-related genes in bladder cancer and their association with cytokeratin 20 messenger RNA. Urol Oncol. 2015;33(12):505.e1-7. doi:10.1016/j.urolonc.2015.07.012

4. Leal J, Luengo-Fernandez R, Sullivan R, Witjes JA. Economic burden of bladder cancer across the European Union. Eur Urol. 2016;69 (3):438-447. doi:10.1016/j.eururo.2015.10.024

5. Berdik C. Unlocking bladder cancer. Nature. 2017;551(7679):S34S35. doi: $10.1038 / 551 \mathrm{~S} 34 \mathrm{a}$

6. Dobruch J, Daneshmand S, Fisch M, et al. Gender and bladder cancer: a collaborative review of etiology, biology, and outcomes. Eur Urol. 2016;69(2):300-310. doi:10.1016/j.eururo.2015.08.037

7. Poli G, Cochetti G, Boni A, Egidi MG, Brancorsini S, Mearini E. Characterization of inflammasome-related genes in urine sediments of patients receiving intravesical BCG therapy. Urol Oncol. 2017;35 (12):674.e19-674.e24. doi:10.1016/j.urolonc.2017.08.004

8. Hausser J, Zavolan M. Identification and consequences of miRNA-target interactions-beyond repression of gene expression. Nat Rev Genet. 2014;15(9):599-612. doi:10.1038/nrg3765 
9. Seok H, Ham J, Jang ES, Chi SW. MicroRNA target recognition: insights from transcriptome-wide non-canonical interactions. Mol Cells. 2016;39(5):375-381. doi:10.14348/molcells.2016.0013

10. Krol J, Loedige I, Filipowicz W. The widespread regulation of microRNA biogenesis, function and decay. Nat Rev Genet. 2010;11 (9):597-610. doi:10.1038/nrg2843

11. Tutar Y. miRNA and cancer; computational and experimental approaches. Curr Pharm Biotechnol. 2014;15(5):429. doi:10.2174/ 138920101505140828161335

12. Romero-Cordoba SL, Salido-Guadarrama I, Rodriguez-Dorantes M, Hidalgo-Miranda A. miRNA biogenesis: biological impact in the development of cancer. Cancer Biol Ther. 2014;15(11):1444-1455. doi:10.4161/15384047.2014.955442

13. Osaki M, Okada F, Ochiya T. miRNA therapy targeting cancer stem cells: a new paradigm for cancer treatment and prevention of tumor recurrence. Ther Deliv. 2015;6(3):323-337. doi:10.4155/tde.14.122

14. Rupaimoole R, Slack FJ. MicroRNA therapeutics: towards a new era for the management of cancer and other diseases. Nat Rev Drug Discov. 2017;16(3):203-222. doi:10.1038/nrd.2016.246

15. Svoronos AA, Engelman DM, Slack FJ. OncomiR or tumor suppressor? The duplicity of MicroRNAs in cancer. Cancer Res. 2016;76 (13):3666-3670. doi:10.1158/0008-5472.CAN-16-0359

16. Blanca A, Cheng L, Montironi R, et al. Mirna expression in bladder cancer and their potential role in clinical practice. Curr Drug Metab. 2017;18(8):712-722. doi:10.2174/138920021866617 0518164507

17. Mitash N, Tiwari S, Agnihotri S, Mandhani A. Bladder cancer: micro RNAs as biomolecules for prognostication and surveillance. Indian J Urol. 2017;33(2):127-133. doi:10.4103/0970-1591.203412

18. Liu Z, Long J, Du R, Ge C, Guo K, Xu Y. miR-204 regulates the EMT by targeting snail to suppress the invasion and migration of gastric cancer. Tumour Biol. 2016;37(6):8327-8335. doi:10.1007/ s13277-015-4627-0
19. Wang X, Qiu W, Zhang G, Xu S, Gao Q, Yang Z. MicroRNA-204 targets JAK2 in breast cancer and induces cell apoptosis through the STAT3/BCl-2/survivin pathway. Int J Clin Exp Pathol. 2015;8 (5):5017-5025.

20. Shuai F, Wang B, Dong S. MicroRNA-204 inhibits the growth and motility of colorectal cancer cells by downregulation of CXCL8. Oncol Res. 2018;26(8):1295-1305. doi:10.3727/096504018X15172747209020

21. Blockus H, Chédotal A. Slit-Robo signaling. Development. 2016;143 (17):3037-3044. doi:10.1242/dev.132829

22. Legg JA, Herbert JM, Clissold P, Bicknell R. Slits and roundabouts in cancer, tumour angiogenesis and endothelial cell migration. Angiogenesis. 2008;11(1):13-21. doi:10.1007/s10456-008-9100-x

23. Li Y, Cheng H, Xu W, Tian X, Li X, Zhu C. Expression of robo protein in bladder cancer tissues and its effect on the growth of cancer cells by blocking robo protein. Int J Clin Exp Pathol. 2015;8(9):9932-9940.

24. Calin GA, Dumitru CD, Shimizu M, et al. Frequent deletions and down-regulation of micro- RNA genes miR15 and miR16 at 13q14 in chronic lymphocytic leukemia. Proc Natl Acad Sci U S A. 2002;99 (24):15524-15529. doi:10.1073/pnas.242606799

25. Mearini E, Poli G, Cochetti G, Boni A, Egidi MG, Brancorsini S. Expression of urinary miRNAs targeting NLRs inflammasomes in bladder cancer. Onco Targets Ther. 2017;22(10):2665-2673. doi:10.2147/OTT. S132680

26. Jafri MA, Al-Qahtani MH, Shay JW. Role of miRNAs in human cancer metastasis: implications for therapeutic intervention. Semin Cancer Biol. 2017;44:117-131. doi:10.1016/j.semcancer.2017.02.004

27. Andrews WD, Barber M, Parnavelas JG. Slit-Robo interactions during cortical development. J Anat. 2007;211(2):188-198. doi:10.1111/ j.1469-7580.2007.00750.x

28. Boles KS, Schmieder AH, Koch AW, et al. MR angiogenesis imaging with Robo4- vs. alphaVbeta3-targeted nanoparticles in a B16/F10 mouse melanoma model. Faseb J. 2010;24(11):4262-4270. doi:10.1096/fj.10157933

\section{Publish your work in this journal}

OncoTargets and Therapy is an international, peer-reviewed, open access journal focusing on the pathological basis of all cancers, potential targets for therapy and treatment protocols employed to improve the management of cancer patients. The journal also focuses on the impact of management programs and new therapeutic agents and protocols on patient perspectives such as quality of life, adherence and satisfaction. The manuscript management system is completely online and includes a very quick and fair peer-review system, which is all easy to use. Visit http://www.dovepress.com/ testimonials.php to read real quotes from published authors. 